\title{
Origins and impact of the term 'NSAID'
}

\author{
Jonas Kure Buer \\ Department of Social Anthropology, University of Oslo \\ Postboks 1091 Blindern \\ 0317 Oslo, Norway \\ e-mail: j.k.buer@sai.uio.no
}

\begin{abstract}
This article is an historical investigation of the term non-steroidal anti-inflammatory drugs and its acronym NSAIDs. Drug names and categories tend to be taken at face value in everyday practice, as natural categories existing in their own right. The main argument of this article is that the term NSAID is a reminder that drug names and categories are in fact complex cultural and social products that have been created by specific people, for specific purposes, through specific historical processes, and that this is relevant for their use today. The article locates the first appearances of the phrase non-steroidal at the entry to the 1960s, when the iatrogenic tragedies that followed from the introduction of corticosteroids had become apparent, and where a clear separation between these drugs and emerging anti-inflammatory alternatives was needed. The article then shows how both the phrase and the acronym appeared for the first time out of specific textual contexts in publications by Michael W. Whitehouse, before they were taken up by a wider community and transformed into concepts independent on the context of their first appearances.
\end{abstract}

\section{Keywords}

NSAID; history; drug names; drug categories; communication

\section{Origins and impact of the term 'NSAID'}

In 2012, I did ethnographic fieldwork in a rheumatology ward. The purpose was to study processes of interaction of health care workers and patients. The term NSAID was in frequent use in a way that attracted my interest: It referred to a number of drugs, but the name NSAID did not seem to add much meaning. Even when written out in full as nonsteroidal anti-inflammatory drugs the term did not say much about the drugs it comprised, other than their being anti- inflammatory, like so many other anti-rheumatic drugs. However, in addition, the term NSAID curiously identified what the drugs it referred to were not: they were not steroids. Why was it necessary, and even pertinent, to communicate that Diclofenac, for instance, was not Prednisolone? In 2012, Prednisolone and other steroids had for several decades been used at low-dose against rheumatic diseases (Case, 2001:130), and to me as a newcomer to the field, steroids seemed to be a standard, conventional part of the rheumatologists' tool kit. Defining a different group of drugs as not steroids did not immediately make sense.

Looking into the matter, I soon realized that the term NSAID, like a lot of other terms in medicine, was not easy to examine historically. NSAIDs do "...have antiinflammatory, analgesic, and antipyretic properties" (Klippel et al., 2010:205); what they don't have is a recorded history. Yet, in the case of NSAIDs, the two first letters of the NSAID acronym turned out to function as a time capsule, making it possible to set the directions for inquiries of the past where the term originated. It turned my attention to the introduction to medicine of the thing that NSAIDs are not - namely anti-inflammatory steroids.

\section{The introduction of corticosteroids}

In 1941 Hans Selye had given the first scientific description of corticosteroids (Selye, 1941a, Selye 1941b). ${ }^{1}$ Then in 1949 a corticosteroid treatment was presented for the first time in medicine. It was arguably a cure for rheumatic arthritis (Case, 2001:130), and the first anti-rheumatic drug with disease modifying ${ }^{2}$ properties (Whitehouse, 2011:2). As

\footnotetext{
${ }^{1}$ The Editors thank Professor Ludmila Filaretova, St Petersburg for her knowledge on the original scientific discovery of corticosteroids.

${ }^{2}$ More than two decades should pass before the term disease-modifying
} 
the news leaked from the conference room to the press, steroids came to be presented as "a genuine miracle cure", and already the following year the individuals behind its discovery received the Nobel Prize (Le Fanu, 2011:33). A long feature article in the June 1951 issue of Popular Science (Pfeiffer, 1951) provides a salient example of the enthusiasm that the discovery of steroids spurred:

The hormones [ACTH and cortisone] represent an entirely new approach in the art of healing. Penicillin, streptomycin, the sulfa drugs, and most other medicines you've been reading about are poisons intended specifically to attack invading germs. (...) But ACTH and cortisone are not germ-killers. They are natural products, gland hormones. They influence the body's builtin chemical factories that go into action whenever extra supplies of tissue are required.

Using rheumatoid arthritis as example, journalist John E. Pfeiffer elaborated on the miraculous effects of steroids:

The hormone can reshape (...) a deformed joint into a smoothly working fulcrum. Pain disappears, and the accumulated debris dissolves. Furthermore, destruction of supporting tissue is stopped in its tracks for months and fresh cells may come in to repair the damage.

While Pfeiffer was aware that there were side-effects to the drug, he seemed to interpret those as just other marvels of the miracle:

No modern drugs have so many bizarre and baffling effects, wanted and unwanted. How do ACTH and cortisone produce excess hair growth and a moon-shaped face? Why do they increase the multiplication rate of tuberculosis germs and at the same time prevent the disease from spreading in the early stages?

He perceived the ability to induce euphoria in patients as "perhaps the most intriguing effect of all":

Cortisone and ACTH are potent 'pep' preparations. Patients experience a marked mental lift after the first doses. They sleep only four or five hours a night, and don't seem to mind it.

In the meantime, physicians and patients learned that the side-effects of treatment with these steroids - “...the moon face, the perforated and bleeding ulcers, the bruising and crushed vertebrae..."(Le Fanu, 2011:34) - were all but marvels. The year Pfeiffer published his article in Popular Science, the first monograph on steroids' adverse effects (Derbes and Weiss 1951) was also published (Whitehouse 2011:2). Gradually rheumatologists realized that the miracles came at too high a price. Popularity waned and by

anti-rheumatic drug (DMARD) was coined. the early 1960s, steroid treatment was "shunned altogether by the rheumatology community" (Case, 2001:130). An anti-steroid zeitgeist arose, and although steroid treatment was reborn in the 1980s as a low-dose regimen, its use remained controversial (Case, 2001:130).

Following, on this background it seems reasonable to formulate the hypothesis that the concept of NSAIDs had been coined not only after the emergence of steroid therapy in 1949, but also after the fall from prestige of steroids in rheumatology around 1960, and before the revival of steroids as a low-dose treatment in the 1980s. PubMed searches for the term (on May 5 2014) point to the early 60s as the origin of the term "non-steroid": The earliest mention of "non-steroid anti-inflammatory" that I was thus able to pinpoint was in the article "A biochemical distinction between non-steroid anti-inflammatory and analgesic drugs" (Whitehouse, 1963).

A necessary separation

I identified the author of this 1963 article as Professor Michael W Whitehouse of Griffith University, Brisbane Australia. ${ }^{3}$ As I asked Professor Whitehouse to share any information he might have on the forging and popularizing of the terms non-steroid anti-inflammatory and NSAIDs, Whitehouse described a situation where the steroids and their analogues had been overused and mis-prescribed. Their euphoric properties had induced addiction in patients, and severe side effects had transformed the hopeful sufferers into "steroid-wrecks" i.e. "patients with ulcers, fragile skin, osteoporosis, impaired immune responses and damaging cartilage repair."

In the late 1950s and early 1960s, a different family of drugs developed from phenylbutazone (indomethacin and flufenamic acid among others being introduced in the 1960s), while pharmaceutical companies were competing to introduce 'super steroids', failing to disclose the full sideeffects. ${ }^{4}$ The record of iatrogenic tragedies that steroids had accumulated, and the problems of deciding whether any new drug was or wasn't related to the known steroids, and thus determining the risks related to it, called for moves that could clarify the situation. In the early 1960s, no known mechanism or other known characteristic could distinguish from steroids the drugs that were soon to be known as NSAIDs.

Whitehouse was in the middle of research that provided him with the right point of view to produce a conceptual tool able to make just such a distinction. Having earned his D Phil from the University of Oxford in 1955, he had relocated to the Department of Physiological Chemistry at the University of Pennsylvania in Philadelphia. There he had become acquainted with Howard Holzer and Jay Lash, after department chairman Sam Gurin had suggested he go and see them in the Anatomy department, one floor below, to discuss alternatives to histological staining as ways to

\footnotetext{
${ }^{3}$ Personal communication May 2014.

${ }^{4}$ For details on this, see "Anti-inflammatory glucocorticoid drugs: reflections after 60 years" (Whitehouse 2011).
} 
characterize embryonic cartilage and distinguish it from embryonic muscle:

\begin{abstract}
'Borrowing' their tissue culture system for initiating cartilage development from embryonic chicken somites, it was easy to confirm that [antiinflammatory] steroids poisoned this process.
\end{abstract}

From pragmatic solution to independent concept

Upon his return to Oxford in 1959, Whitehouse analyzed the data from the experiments he had conducted in Philadelphia, and in 1960 he presented the first results at the first International Congress of Endocrinology, Copenhagen. It is in the proceedings to that congress, in a short paper entitled "Effect of hydrocortisone and some of their synthetic analogues upon the biogenesis of cartilage in vitro" (Whitehouse and Lash, 1960), that Whitehouse used the phrase non-steroid anti-inflammatory for what was probably the first time:

We have studied the effects of a number of glucocorticoids and also of some non-steroid anti-inflammatory agents upon the biogenesis of cartilage in tissue culture.

The following year, the final version of that paper was published as an article in Nature: "Effect of cortisone and related compounds on the biogenesis of cartilage" (Whitehouse and Lash, 1961). In the article, results with different substances were grouped together under three separate headings: "Results with Cortisone and Hydrocortisone", "Results with Some Synthetic Glucocorticoids", and "Results with some Non-Steroid Anti-inflammatory Agents". Further the term non-steroid appeared twice in the text, in the introduction and in the conclusion, in the following sentences:

For comparison we also observed the effects of some non-steroid inflammatory agents upon this system in vitro.

This desirable end is found otherwise with certain non-steroid drugs, for example phenylbutazone.

It is interesting to note that the use of non-steroid in these examples can be read as merely resulting from the logic of the text. The phrase appears within the pattern ' $\mathrm{X}$, and non$\mathrm{X}$ ' (where steroids are $\mathrm{X}$ and where "for example phenylbutazone", which is not a steroid, is referred to as non-X). This separation categorized, within the context of the article, all substances that had been tested. Nothing in the text indicates that this was more than a pragmatic solution, or that a new concept was about to be introduced to medicine.

But by 1963, however, it is clear that the phrase that appeared in the 1960 and 1961 publications had been established as an independent concept. In the article "A Biochemical Distinction Between Non-Steroid Antiinflammatory and Analgesic Drugs" (Whitehouse, 1963), the term non-steroid figures for the first time in a heading, but more importantly, the non-X (the non-steroid) appeared in a linguistic context where there was no mention of the $\mathrm{X}$ (the steroid). Conversely and rather unusually, the distinction that was drawn was now between non- $\mathrm{X}$ and $\mathrm{Y}$, i.e. between "Non-Steroid Anti-Inflammatory Drugs" and "Analgesic Drugs." That the phrase non-steroid antiinflammatory drugs had been taken up as a concept by a wider research community was evident when in September 1964 an "International symposium on non-steroidal antiinflammatory drugs" was organized in Milan, resulting in the publication of a book (Garattini and Dukes, 1965) with the term in its title.

Acronym and concept-acronym

Still, during the $1960 \mathrm{~s}$, the drugs were referred to as nonsteroidal anti-inflammatory drugs, not as NSAIDs, as they often are today. Ten years seem to have passed before the concept-phrase was challenged in use by its acronym. In 1973, Paulus and Whitehouse published an article titled "Nonsteroid anti-inflammatory agents" (Paulus and Whitehouse, 1973), and at the bottom of the first page, the authors use the acronym, for the first time, in the following sentence:

Demonstration of the anti-rheumatic properties of these new drugs (...) establishes to some degree the validity of the rat edema assays for selecting moderately effective nonsteroidal "antiinflammatory" drugs (NSAIDs).

The acronym was introduced, it seems, in compliance with norms of using acronyms sparingly and fully explained when first used. The ambition of the authors, clearly, was not to introduce a new term, but to communicate their research results to their readers.

As with the term non-steroid in 1960, it therefore seems as though the appearance of the acronym NSAID was somehow brought forward by the internal logics of research publishing. In a similar way to how the phrase non-steroid anti-inflammatory had become concept in its own right, the acronym NSAID was soon established as an independent concept with no need of explanation. By the late 1970s, the acronym even figured in the titles of scientific journal articles: "Possible causes of treatment failure with the NSAID" (Gylding-Sabroe, 1978), and "Relation between ulcerogenic activity of various NSAID and their potency as inhibitors of prostaglandin synthesis in vivo" (Strub and Muller, 1979), being the two earliest examples of this in PubMed.

Subsequently, the acronym-concept gained popularity and widespread use: A PubMed search (on June 3 2014) on the term NSAID, resulted in 191.349 hits. A Google search that same day resulted in 4.420 .000 hits in 0,11 seconds. Today, the term NSAID is so widely used that it seems difficult to conceptualize any discourse on drug treatments in rheumatology without it. In Whitehouse's own words:

Though clumsy, the acronym NSAIDs seemed to 
have served us well; for example, reassuring physicians that their use will not produce pseudosteroid wrecks, though their patients may still suffer stomach (but not skin) ulcers and in extreme cases intestinal perforation.

It is perhaps not insignificant that the popularization of the acronym NSAID as an independent concept, which played down the message of caution against steroids, coincided with a rising awareness of the dangers associated with NSAIDs themselves.

\section{Conclusions}

The term NSAID seems to have been born from a perceived need to distinguish new anti-inflammatory drugs from steroids, and from the determination of a young researcher, Michael Whitehouse, to separate his biochemical studies on salicylates and other acidic anti-inflammatories "from the odium associated with the anti-inflammatory steroids." It seems that it was the perceived need to separate these drugs from the steroids, and the absence of a clear logic for internal identification of the emerging group of antiinflammatory drugs, was what led Whitehouse to use the term "non-steroidal anti-inflammatory". Doing so, he forged a category that reflected his research findings, and which defined this emerging field of research at an early point. At the same time, the term that he introduced answered to needs outside of laboratory research - i.e. in clinical practice and public discourse. The concept non-steroid antiinflammatory proved useful in the 60 s as a tool for handling the complexities of inflammopharmacology, by signaling what it was not. Later the NSAIDs were to be associated with their own series of severe iatrogenic effects, while the term as such remained robust. What was introduced as a warning has become a thing - and it continues to be useful, we must assume, though perhaps for totally different reasons. For me, it has been useful as an entry point into the rather impenetrable but immensely interesting history of development of cultural categories in pharmacology.

In the excavations I have relayed above, we may well have identified the time when the term was coined, the context of the coining, and even the originator's reasons for coining it. We may have appreciated some of the uses the term have served, and serves today. But we can only speculate on the total impact that the rather serendipitous introduction of this term has had on rheumatology, on pharmacology in general, on drug development, research finance, marketing; on clinical communication, patient safety, and so on - over the 50 years since its coining. A perceived need to minimize harm to the patient, deflecting attention away from the steroids as prime therapy, seems to have been a driving force behind this striking development. On a more detailed level, this has required that the term be perceived, again and again, as answering to a number of needs of a multitude of social actors, actors who have found it opportune to perpetuate the use of its term, until the point where its use ceased to be a choice, became reflex, and the term was established as an entity in its own right.

The concept seems to have been naturalized in the sense that
NSAIDs and "non-steroidal anti-inflammatory drugs" appear almost as an a priori category, as though the category existed before the individual drugs that the category comprises appeared, even before the discovery of the steroids. This is perhaps the most interesting insight we can draw from this investigation. In medical literature and everyday language and practices, drug categories such as NSAIDs are often taken at face value, as phenomena existing in their own right. The term NSAIDs remind us that these categories are not a priori given; they have been created by specific people, for specific purposes, through specific historical processes. They could be different, and they needn't be at all, but being - as complex cultural, social, historical creations - and being exactly what they are, they have worked not only in our world, but also on it, and continue to do so.

Jonas Kure Buer

$\mathrm{PhD}$ fellow

Department of social anthropology

University of Oslo

Norway

Acknowledgments: I am heavily indebted to Professor Michael Whitehouse and Professor KD Rainsford for encouraging an historical commentary on this topic, and for providing informational fixed points that allowed me to make the step from speculations to facts. Thanks to Professor Whitehouse for sharing his memories and insights about the origin of the term, and for proofreading my analysis. Thanks also to Professor KD Rainsford for checking for other early appearances in rheumatological literature from the period, including several of Derek Willoughby's papers and more (Gourley, 1964, Rechenberg and Kunz, 1962, Dixon et al., 1963, Smith and Smith, 1966). Thanks to Professor KD Rainsford's verifications, it seems even safer to identify Michael Whitehouse as the originator of the term "non-steroidal anti-inflammatory" drugs, as well as of the NSAID acronym. Any misinterpretations or other mistakes are entirely mine. I will be thankful to anyone who points this out for me. I also want to underscore that the identification of Michael Whitehouse as originator of the terms is based on my investigations as well as KD Rainsford's verifications, and that Michael Whitehouse has not made any claims on his own behalf; he has merely contributed with a personal account that does not contradict, but supports, the hypothesis.

\section{References}

CASE, J. P. 2001. Old and New Drugs Used in Rheumatoid Arthritis: A Historical Perspective: Part 1: The Older Drugs. American Journal of Therapeutics, $8,123-143$.

DERBES, VJ, WEISS TE. 1951. Untowards reactions of cortisone and ACTH. Blackwells Scientific Publications, Oxford

DIXON, A., MARTIN, J., SMITH, B. \& WOOD, M. 1963. Salicylates: an international symposium, sponsored by the Empire Rheumatism Council, with the support of the Nicholas Research Institute Ltd, London, Churchill.

GARATTINI, S. \& DUKES, M. N. G. 1965. International symposium on non-steroidal anti-inflammatory 
drugs: 8-10 September 1964 - Milan, Amsterdam, Excerpta Medica Foundation.

GOURLEY, D. R. H. 1964. Basic Mechanisms of Drug Action. In: JUCKER, E. (ed.) Fortschritte der Arzneimittelforschung / Progress in Drug Research / Progrès des recherches pharmaceutiques. Birkhäuser Basel.

GYLDING-SABROE, J. P. 1978. Possible causes of treatment failure with the NSAID. Rheumatol Rehabil, Suppl, 90-3.

KLIPPEL, J. H., STONE, J. H., CROFFORD, L. J. \& WHITE, P. H. 2010. The Pocket Primer on the Rheumatic Diseases, London, Springer London.

LE FANU, J. 2011. The rise and fall of modern medicine, London, Abacus.

PAULUS, H. E. \& WHITEHOUSE, M. W. 1973. Nonsteroid anti-inflammatory agents. Annu Rev Pharmacol, 13, 107-25.

PFEIFFER, J. E. 1951. How Hormone Team Is Saving Lives. Popular Science, June.

RECHENBERG, H. K. V. \& KUNZ, H. A. 1962.

Phenylbutazone: butazolidin, London, E. Arnold.

SELYE, H. 1941a. Pharmacological classification of steroid hormones. Nature, 148,84-95
SELYE, H 1941b. On the hormonal activity of a steroid compound. Science, 94, 94.

SMITH, M. J. H. \& SMITH, P. K. 1966. The salicylates: a critical bibliographic review, New York, Interscience Publishers.

STRUB, K. M. \& MULLER, R. K. 1979. Relation between ulcerogenic activity of various NSAID and their potency as inhibitors of prostaglandin synthesis in vivo. Agents Actions Suppl, 245-54.

WHITEHOUSE, M. W. 1963. A Biochemical Distinction Between Non-Steroid Anti-inflammatory and Analgesic Drugs. Journal of Pharmacy and Pharmacology, 15, 556-557.

WHITEHOUSE, M. W. 2011. Anti-inflammatory glucocorticoid drugs: reflections after 60 years. Inflammopharmacology, 19, 1-19.

WHITEHOUSE, M. W. \& LASH, J. W. 1960. Effect of hydrocortisone and some of their synthetic analogues upon the biogenesis of cartilage in vitro. Proceedings of the first International Congress of Endocrinology, Copenhagen 1960.

WHITEHOUSE, M. W. \& LASH, J. W. 1961. Effect of Cortisone and Related Compounds on the Biogenesis of Cartilage. Nature, 189, 37-39 